\title{
O QUE ACONTECE DURANTE O PERÍODO DE ESPERA? CONTRIBUIÇÕES PARA O ESTUDO DO AUTOCONTROLE
}

\section{WHAT HAPPENS DURING THE WAITING PERIOD? CONTRIBUTIONS TO THE STUDY OF SELF-CONTROL}

\author{
LUIZ ANTONIO BERNARDES \\ NILZA MiCHELETTO \\ PontifícIa Universidade Católica de SÃo PaUlo, BRASIL
}

\section{RESUMO}

Este estudo verificou os efeitos do controle social sobre o comportamento de autocontrole em crianças. Os participantes foram distribuídos em três condições de espera: 'sozinha', 'fantoche' com possível função de audiência, e 'duplas'. Elas deveriam esperar 15 minutos pelo retorno do experimentador para obter dois chocolates ou tocar um sino para chamar o experimentador e receber apenas um. Crianças da condição 'sozinho' foram as que menos esperaram. A categorização das respostas no período de espera indicou que o menor número de respostas por minuto ocorreu para os que não esperam. Nas 'duplas', houve maior quantidade de respostas nas diferentes categorias, maior variabilidade no responder e pôde-se identificar que o outro dispõe consequências adicionais às manipuladas pelo indivíduo, favorecendo o autocontrole.

Palavras-chave: autocontrole, reforçador imediato, reforçador atrasado, controle social, análise do comportamento, crianças

This study examined the effects of social control on children`s self-control. The participants were assigned to three waiting conditions: 'alone', 'hand puppet' serving as a possible audience, and 'peers'. Children should choose between waiting 15 minutes for the experimenter in order to get two chocolates or ringing a bell during that interval to call the experimenter and get only one. The participants exposed to the 'alone' condition waited less time than the children exposed to the other conditions. The categorization of responses in the waiting period indicated that fewer responses per minute occurred for those who did not wait. On the 'peers' condition, it was observed a greater number of responses in the different categories, greater variability in responding, and that the peers provided additional consequences to those manipulated by the individual, improving self-control.

Keywords: self-control, immediate reinforcer, delayed reinforcer, social control, behavior analysis, children

O trabalho foi conduzido no contexto da pesquisa de Mestrado, parcialmente financiada pela CAPES, do primeiro autor, sob orientação da segunda autora. Correspondência para Luiz Antonio Bernardes. Endereço: - Rua Cel. Otávio Meyer, 160, sala 230. CEP 37550-000 - Centro - Pouso Alegre - MG - Brasil. E-mail: luaber@ yahoo.com.br. Agradecemos à Tereza Maria de Azevedo Pires Sério pelas contribuições no início desse trabalho. 
O autocontrole, para Skinner (1953/1965), envolve uma situação na qual existem dois cursos de ação distintos, cujas consequências variam em relação a algumas de suas propriedades (temporalidade, magnitude e/ou natureza), gerando assim uma situação de conflito. Skinner afirma que um indivíduo controla seu comportamento como controlaria o de outras pessoas; por meio de uma resposta (controladora) altera a probabilidade de outra (controlada), manipulando variáveis do ambiente.

Vários analistas do comportamento conduziram experimentos que buscavam descrever contingências que favoreceriam comportamentos denominados de autocontrole (Hanna \& Todorov, 2002), tanto por meio de pesquisa básica (Rachlin \& Green, 1972; Grosh \& Neuringer, 1981; Siegel \& Rachlin, 1995) como em pesquisas aplicadas abordando problemas relacionados ao consumo de alimentos (Ferster, Numberger \& Levitt, 1973), consumo de drogas (Rachlin, 2000), comportamentos de crianças hiperativas (Neef, Bicard, \& Endo, 2001; Menezes, 2007).

Estudos sobre autocontrole têm sido conduzidos com sujeitos não humanos, adultos e crianças. Alguns autores destacam a importância de estudos com crianças para compreender processos envolvidos na sua origem (Mischel \& Ebbesen, 1970), tendo em vista que alguns resultados que indicam que autocontrole é mais encontrado em adultos do que em crianças, e para o desenvolvimento de técnicas de ensino de comportamentos denominados de autocontrole em crianças (Lougue \& Chavarro, 1992).

Mischel e colaboradores (e.g., Mischel \& Ebbesen, 1970; Mischel, Ebbesen, \& Zeiss, 1972) manipularam atraso e magnitude dos estímulos reforçadores e destacaram seu interesse por variáveis que poderiam interferir no tempo que crianças esperaram por reforçadores de maior magnitude, bem como nas atividades que crianças realizam enquanto esperam.

Mischel e Ebbensen (1970), por exemplo, investigaram o tempo que crianças conseguiam esperar para a obtenção de reforçadores, por meio da manipulação da presença do estímulo reforçador e de estímulos com diferentes preferências. De maneira geral, o procedimento experimental consistia na apresentação de dois estímulos comestíveis à criança, um dos quais era claramente o preferido por ela, conforme determinado em um pré-teste. Para obter o estímulo preferido, a criança deveria esperar até que o experimentador retornasse à sala por conta própria. Se ela solicitasse a volta do experimentador, o estímulo menos preferido era disponibilizado. Quatro condições foram planejadas para avaliar a influência do contato visual com os estímulos reforçadores e o comportamento de espera: (i) esperar com os dois estímulos à vista; (ii) sem nenhum deles; (iii) com o mais ou (iv) com o menos preferido à vista. A variável dependente foi o tempo transcorrido entre a saída do experimentador e o seu retorno. As crianças que tiveram os estímulos à vista esperaram menos tempo do que aquelas que não tiveram. Os autores observaram as estratégias que as crianças usavam para permanecer esperando: evitavam manter contato visual com as gratificações, cobriam os olhos com as mãos, apoiavam as cabeças sobre os braços, falavam consigo mesmas, cantavam, brincavam com as mãos e os pés e tentavam dormir. Os resultados do estudo de Mischel e Ebbesen (1970) levaram os autores a concluir que as atividades distrativas possibilitavam que os participantes esperassem mais tempo.

Mischel et al. (1972), com o objetivo de investigar o papel de instruções para pensar em algo, como um tipo de atividade distrativa para o comportamento de espera, realizaram três experimentos com procedimentos similares aos de Mischel e Ebbesen (1970).

Em todos os três experimentos de Mischel et al. (1972) havia três grupos. Os autores introduziram um sino que as crianças tocavam para que o experimentador retornasse, caso não conseguissem esperar. No Experimento I, com estímulos - um pretzel e um marshmallow - sempre à vista das crianças, enquanto esperavam o retorno do experimentador, exceto no Experimento III, (i) um grupo recebeu a instrução para pensar em coisas divertidas, (ii) outro grupo teve um brinquedo disponível e não teve a instrução para pensar em coisas divertidas, e (iii) o último grupo não teve instrução para pensar em coisas divertidas nem o brinquedo. Nesse experimento foi observado um tempo médio de espera baixo no grupo sem instruções e no grupo que teve um brinquedo.

No Experimento II, (i) um grupo recebeu instrução para pensar em coisas divertidas sem relação com os estímulos à vista; (ii) um grupo para pensar em coisas ruins, e (iii) outro para pensar nos estímulos à vista. Os autores concluíram que as crianças esperavam mais tempo pelo experimentador quando instruídas para pensar em coisas divertidas sem relação com o estímulo à vista do que quando instruídas a pensar no estímulo à vista ou sobre coisas ruins.

O Experimento III foi delineado com três grupos com condições iguais às do Experimento II, tendo como única alteração os estímulos (pretzel e marshmallow) terem sido retirados da vista das crianças. Os resultados do Experimento III indicaram que mesmo quando os estímulos reforçadores não estão à vista, pensar sobre eles serviu para diminuir o tempo de espera.

Em ambos os estudos, a presença do estímulo ou a instrução para pensar sobre ele parece ter diminuído o tempo de espera. E, com base nas observações experimentais sobre o que as crianças faziam enquanto esperavam, os autores sugerem que respostas possíveis de serem observadas ou instruções para pensar em estímulos reforçadores poderiam influenciar o tempo de espera.

Grosh e Neuringer (1981) utilizaram, com pombos, procedimentos análogos aos dos estudos de Mischel, manipulando diversas variáveis, entre elas as atividades realizadas durante o período de atraso do 
reforçador de maior magnitude. Neste estudo, caso o pombo não emitisse respostas de bicar um disco recebia o reforçador (alimento) preferido; caso bicasse um disco iluminado (análogo ao sino dos experimentos de Mischel), recebia o menos preferido. No Experimento I os autores buscaram determinar se a visão dos estímulos mais e menos preferidos aumentaria ou não o tempo de espera. Na caixa experimental havia dois dispensadores de alimentos com uma porta plástica, pela qual os pombos poderiam ver os alimentos utilizados no experimento. Os pombos passaram por três fases experimentais: reforçadores visíveis, reforçadores não visíveis e uma reversão à primeira fase com os reforçadores visíveis. Os resultados foram similares aos de Mischel e Ebbesen (1970): os pombos geralmente bicavam o disco iluminado quando o alimento estava visível. No Experimento II, os autores investigaram se a oportunidade para a emissão de uma resposta alternativa (bicar um disco na parede oposta) aumentaria o período de espera. Para isso os pombos foram modelados a bicar um disco na parede oposta que produzia outro tipo de alimento em um esquema de reforçamento intermitente de Razão Fixa 20. Os resultados mostraram que o período de espera aumentou para os pombos quando tinham oportunidade de uma resposta alternativa.

Os trabalhos descritos apontam que, em sujeitos humanos e não humanos, a espera por reforçadores de maior magnitude ou preferidos está relacionada com a presença do estímulo reforçador e com as respostas emitidas pelos sujeitos durante o tempo de espera.

Assim como na literatura internacional, alguns estudos brasileiros feitos com humanos, analisaram as respostas durante o período de atraso (Canavarros, 2009; Correia \& Micheletto, 2015; Fernandes, 2005; Kerbauy, 1981; Kerbauy \& Buzzo, 1991; Menezes, 2007)

Kerbauy (1981) analisou o comportamento de crianças durante o período de espera em um estudo em que elas deveriam esperar para ganhar dois tipos diferentes de chocolate (mais ou menos preferidos) que ficavam à vista delas. Da mesma forma que nos estudos de Mischel, a variável dependente era o tempo de espera. Os resultados indicaram que 10 das 12 crianças esperaram, mesmo tendo estímulos à vista. A autora apresenta algumas das respostas emitidas pelas crianças durante o período de espera: brincar com as mãos, com um carrinho que não era da situação experimental, com um elástico e com as pernas; olhar em direção à fresta por onde a observadora fazia suas observações e murmurar enquanto ficavam sentadas. A autora defende que mesmo em situações ambientais pouco estimuladoras, o indivíduo é capaz de produzir suas próprias atividades, isto é, ele é capaz de emitir respostas que podem ser incompatíveis com as respostas de encerramento da sessão (toque do sino).

Kerbauy e Buzzo (1991) ampliaram e sistematizaram a análise dos comportamentos emitidos durante o período de espera em um estudo em que buscaram verificar se a própria reexposição à situação experimental favoreceria a aprendizagem de esperar por reforçadores maiores e atrasados. O procedimento foi semelhante ao de Mischel et al (1972). Havia dois grupos, (i) um que poderia ver as balas que receberiam caso esperassem, e o (ii) outro que não poderia ver as balas. Os participantes que não conseguiram esperar eram reconduzidos à sessão no dia seguinte, até que conseguissem esperar os 15 minutos. Dos 27 participantes da pesquisa, aproximadamente metade esperou em cada uma das condições, na primeira oportunidade para esperar. Os resultados indicaram que os grupos não diferiram entre si em relação a esperar e ao fato de verem ou não as balas e que a exposição repetida ao procedimento levou as crianças que inicialmente não esperaram a esperar. Ampliando a análise realizada no estudo de Kerbauy (1981), Kerbauy e Buzzo (1991) sistematizaram os comportamentos emitidos pelas crianças durante o período de espera em algumas categorias: motores, de exame do ambiente, verbais e/ou gestuais, dirigidos à situação experimental e de automanipulação.

Os estudos que investigam a relação entre as atividades de uma criança no período de espera por reforçadores atrasados podem favorecer a compreensão de variáveis de controle de comportamentos que produzem reforçadores atrasados quando em conflito com comportamentos que produzem reforçadores imediatos.

Skinner (1953/1965), ao abordar técnicas de controle, descreve uma série de condições que tornam ações chamadas de autocontrole possíveis. Skinner destaca que, além de examinar tais condições, é necessário explicar por que os indivíduos as colocam em prática, especialmente se o objetivo é gerar autocontrole. Controles adicionais dispostos pela comunidade são, segundo Skinner, responsáveis pela maioria dos comportamentos de autocontrole. A sociedade dispõe outras variáveis no ambiente e na história do indivíduo, que os favorecem. O ambiente social opera criando condições que aumentam a probabilidade de tais comportamentos.

De interesse especial no presente trabalho são as variáveis relacionadas ao controle social que podem interferir no comportamento de autocontrole. Investigar o comportamento de esperar por reforçadores de maior magnitude e atrasados em condições ambientais em que o controle social pode estar presente pode ampliar o conhecimento de condições em que se busca gerar e manter comportamentos denominados de autocontrole.

A influência do ambiente social no comportamento foi estudada, entre outros, por Moroz (1991) ao investigar solução de problemas. A autora analisa o papel de outro indivíduo em situações de resolução de problemas, especialmente como uma condição que poderia propiciar a descrição de eventos que ocorrem na resolução de problema, que, como o autocontrole, é descrito por Skinner (1953/1965) como um comportamento complexo. A autora estudou estratégias de resolução de problemas com crianças pré- 
escolares observadas em situações não programadas por ela (sala de aula e situações livres). As interações observadas poderiam ocorrer tanto individualmente (a criança e o objeto) quanto em grupo de crianças ou crianças e adultos. Moroz afirma que quando crianças são colocadas em condições em que tenham que trabalhar com outras pessoas, elas aumentam a emissão de respostas verbais abertas. Segundo a autora, a presença de outra pessoa pode ser condição que propicia a descrição de eventos encobertos que participam na solução de problemas.

$\mathrm{O}$ aumento das respostas verbais, identificado no estudo de Moroz (1991), parece estar relacionado à função da audiência analisada por Skinner (1957/1992). Fonai e Sério (2007), na análise do conceito de audiência proposto por Skinner (1957/1992), apontam que ele salienta a audiência como sendo parte da condição antecedente para a emissão de uma resposta verbal, e que tem dupla função: a função de estímulo discriminativo e a função de estímulo reforçador. A audiência como estímulo discriminativo é condição para ocorrência dos operantes verbais e tem função evocativa de formas específicas de respostas do falante.

Pasquinelli (2007) estudou controles sociais sobre o comportamento ao investigar o controle exercido pela audiência, utilizando fantoches. Eles poderiam ser fantoches de treino e de teste. Respostas verbais vocais dos participantes diante de filmes e na presença de diferentes fantoches eram reforçadas. Cada fantoche consequenciava, com fichas que poderiam ser trocadas por brinquedos, um de dois conjuntos diferentes de respostas: um fantoche consequenciava o repertório ' $\mathrm{f}$ ', composto de descrições de características físicas dos personagens dos filmes e/ou características observáveis retratadas, e outro fantoche consequenciava o repertório ' $\mathrm{m}$ ' que envolveu respostas consideradas mentalistas (finalidades e emoções nos personagens). Pasquinelli (2007) identificou que o procedimento permitiu estabelecer os fantoches como audiências reforçadoras de modo que dois repertórios distintos foram estabelecidos em função da história de reforçamento estabelecida na presença de cada um dos fantoches. Também se observou que os fantoches tornaram-se estímulos com função discriminativa sobre a resposta verbal dos participantes, visto que nas situações de teste cada fantoche evocava o conteúdo da fala do participante que tinha consequenciado. Ou seja, o estudo mostrou que a audiência foi uma variável relevante na seleção de aspectos descritos sobre o filme, exercendo a dupla função sugerida por Skinner.

Atividades durante o período de espera foram identificadas como importantes para a emissão de respostas de crianças que produzem reforçadores maiores e atrasados em situações de conflito com respostas que produzem reforçadores menores e imediatos (Kerbauy, 1981; Kerbauy \& Buzzo, 1991; Mischel \& Ebbesen, 1970; Mischel et al, 1972). Tais resultados foram produzidos em condições em que crianças estavam sozinhas. A ressalva de Skinner sobre as "fontes últimas de controle" geradas pelo ambiente social, que fornece condições adicionais às manipuladas pelo próprio indivíduo para aumentar a probabilidade de comportamentos de autocontrole, indica a importância de se investigar a interferência de possíveis controles sociais sobre esse comportamento.

O objetivo do presente trabalho foi verificar os efeitos do controle social no comportamento de esperar por reforçadores de maior magnitude atrasados em crianças. Para avaliar tais efeitos foram manipuladas três condições. A primeira condição 'sozinho' replicou o modelo já estudado nos experimentos citados, em que nenhum controle social planejado estava presente. Duas outras condições - 'fantoche' e 'duplas' - foram criadas para avaliar condições planejadas em que era possível se estabelecer um controle social: fantoche que poderia na história pessoal ter adquirido a função de audiência e outra criança que, além da função de audiência, poderia interferir nas possibilidades de obtenção de reforçadores.

Buscou-se identificar as relações entre o que se faz no período de espera e o tempo de espera em condições que permitissem avaliar se crianças esperando em duplas ou usando um fantoche teriam maiores tempos de espera, do que esperando sozinhas por reforçadores maiores e atrasados.

O delineamento experimental que se segue teve como objetivo obter dados referentes ao que participantes humanos fazem enquanto esperam. Assim, o conhecimento de possíveis comportamentos relacionados a maiores tempos de espera em função do contexto social poderiam favorecer o planejamento de condições que aumentassem a probabilidade de comportamentos denominados de autocontrole em situações cotidianas.

\section{Participantes}

\section{MÉTODO}

Quinze crianças do primeiro ano do Ensino Fundamental de uma escola pública de uma cidade do interior de Minas Gerais participaram da pesquisa. A idade das crianças variou de 6 anos e 2 meses a 7 anos e 4 meses e a média foi de 6 anos e 7 meses. Os responsáveis pelas crianças assinaram um termo de consentimento livre e esclarecido.

\section{Equipamento, Material e Setting}

A coleta dos dados foi realizada em uma sala na biblioteca da escola que media $7 \times 12$ metros, sendo que o espaço utilizado para a pesquisa era de $3 \times 3$ metros. A área delimitada para a pesquisa continha um armário do lado esquerdo, sobre o qual ficava uma filmadora (Samsung Digital Cam 34x Optical Powerful Zoom), três cadeiras, uma mesa, sobre a qual ficava o sino, um ou dois Kinder ${ }^{\circledR}$ ovos (um chocolate em formato de ovo contendo no seu interior uma embalagem plástica com algum brinquedo já montado ou para montar), ou um fantoche (um boneco de pano 
no formato de uma pessoa), presente em uma das condições experimentais.

\section{Procedimento}

$1^{\text {a }}$ Fase: Apresentação do Kinder ${ }^{\circledR}$ ovo.

Uma semana antes da coleta dos dados foi distribuído um chocolate desse tipo para todas as crianças, para garantir que todas elas conhecessem esse estímulo.

A coleta foi realizada no período de aula. As crianças foram alocadas em três condições por meio de um sorteio: quatro crianças na condição 'sozinho' ( $\mathrm{S} 1$, $\mathrm{S} 2, \mathrm{~S} 3$, e S4), três crianças na condição 'fantoche'( $\mathrm{F} 1$, F2, e F3) e oito crianças na condição 'duplas' (D1-D2, D3-D4, D5-D6, e D7-D8).

\section{experimentador.}

$2^{a}$ Fase: Treino da resposta de chamar o

Todas as fases foram realizadas no mesmo dia para todos participantes. O primeiro passo foi perguntar à criança o que ela preferiria, se um ou dois Kinder ${ }^{\circledR}$ ovos. Após a resposta da criança, era lida a seguinte instrução:

Nós agora vamos fazer uma brincadeira. Em alguns momentos eu terei que sair da sala e quando eu sair, você(s) poderá (ão) me trazer de volta. Para me trazer (em) de volta é só você(s) tocar(em) esta sineta. Você(s) entendeu(ram)? Você(s) pode(m) repetir como funciona? Então agora nós vamos testar como funciona.

Após a instrução, o experimentador saía da sala e retornava após o toque da sineta e isto ocorreu três vezes consecutivas para cada criança. A instrução era repetida caso a criança não descrevesse a contingência contida na instrução. Caso a criança errasse a descrição da contingência em três tentativas, ela ganhava um Kinder ${ }^{\circledR}$ ovo e era dispensada da pesquisa.

\section{$3^{\text {a }}$ Fase: Condições experimentais.}

O experimentador permanecia atrás do armário e observava as crianças durante o período de espera através do visor da câmera filmadora, de forma que a criança não podia vê-lo.

Após a Fase 2, cada participante foi exposto a uma condição experimental. Na condição 'sozinho', a criança permaneceu sozinha na sala e sentada à mesa, com um Kinder $^{\circledR}$ ovo à sua frente em cima da mesa, por um período máximo de até 15 minutos, período utilizado em estudos que foram a base para o presente trabalho (Kerbauy \& Buzzo, 1991; Mischel et al., 1972). O tempo de espera não era informado à criança. Caso ela permanecesse o tempo total, obteria dois Kinder $^{\circledR}$ ovos e se tocasse o sino antes da passagem dos 15 minutos, o experimentador retornava à sala e a criança levava o Kinder® ovo que já estava com ela. A instrução dessa condição foi a seguinte:
Agora que você já sabe como me trazer de volta, eu vou sair, mas antes disso vou deixar com você o Kinder $^{\circledR}$ ovo. Você vai ganhar este Kinder $^{\circledR}$ ovo, caso você me chame de volta, antes que eu volte por mim mesmo. Você se lembra como me traz de volta? Caso você consiga esperar a minha volta, você ganhará mais um Kinder ${ }^{\circledR}$ ovo.

Você entendeu? Diga-me, então, como funciona! Você pode me dizer o que você vai ganhar se me chamar de volta? E se me esperar? Como você faz para me trazer de volta? Se você tocar a sineta e me trouxer de volta o que irá acontecer? E se você não tocar a sineta e esperar? Agora que você já entendeu, eu vou sair e volto daqui a pouco!

Se, após o experimentador ter pedido à criança que repetisse a instrução, ela não repetisse corretamente, o experimentador repetia novamente a instrução por mais duas vezes. A criança deveria responder corretamente a cada uma das questões colocadas. O experimentador esperava a resposta da criança entre uma pergunta e outra. Este procedimento era feito para todas as crianças.

$\mathrm{Na}$ condição 'fantoche', a criança permaneceu sozinha na sala e recebeu a mesma instrução que na condição 'sozinha'. Esta condição teve como diferencial a presença de um fantoche. $\mathrm{O}$ experimentador lia a instrução dada na condição 'sozinho' e depois colocava o fantoche em sua mão e o apresentava a criança:

Este aqui é o meu amigo Pedrinho. Ele me disse que gostaria de lhe conhecer. Você pode contar para ele o que vai acontecer aqui na nossa brincadeira?

Vou deixar com você o meu amiguinho Pedrinho que vai lhe fazer companhia durante o tempo que eu estiver fora. Se você quiser conversar com ele durante o tempo que eu estiver fora, você pode.

Após ter dado todas as instruções e a criança ter respondido corretamente às perguntas feitas, o experimentador deixava o fantoche sobre a mesa, de maneira que a criança pudesse manipulá-lo.

$\mathrm{Na}$ condição 'duplas', o procedimento foi o mesmo das outras condições, porém, cada uma das crianças ficou com um Kinder ${ }^{\circledR}$ ovo à sua frente. A instrução foi igual à da condição 'sozinho' com o seguinte acréscimo:

Agora que vocês já sabem como me trazer de volta, eu vou sair, mas antes disso vou deixar um Kinder ${ }^{\circledR}$ ovo para cada um (a) de vocês. Cada um de vocês ganhará um Kinder ${ }^{\circledR}$ ovo caso me chamem de volta, antes que eu volte por mim mesmo. Vocês se lembram de como me trazem de volta? Caso vocês consigam esperar a minha volta, vocês ganharão outro Kinder ${ }^{\circledR}$ ovo.

Vocês entenderam? Digam-me, então, como funciona?

Todas as sessões foram filmadas. As filmagens foram transcritas demarcando intervalos de $10 \mathrm{~s}$ para a 
tabulação e análise dos dados. A partir das transcrições, as respostas emitidas foram classificadas em 14 categorias construídas com base em Kerbauy e Buzzo (1991) e Danna e Matos (1982):

- Mudança na postura ou posição (MPP) - respostas que mudem o contato já existente do participante com o meio físico (senta sobre as pernas em cima da cadeira; vira o corpo de lado na cadeira, ficando com o lado esquerdo apoiado na mesa; abaixa-se).

- Manipulação de objetos (MO) - contato físico do participante com o meio físico, exceto aqueles relacionados à condição experimental (passa os dedos sobre a superfície da mesa; toca na mesa com as laterais das mãos abertas; balança-se sobre a cadeira).

- Manipulação de pessoas (MP) - contato do participante com o outro participante (afasta o rosto do outro P; estica o pescoço na direção do outro $\mathrm{P}$; ser tocado pelo outro $\mathrm{P}$ ).

- Exame ou observação do ambiente (AMB) observação do ambiente físico experimental (olha em direção à porta da frente ao som da porta se fechando; olha para a porta; olha para cima/baixo; olha para o outro, na condição dupla).

- Respostas motoras repetitivas (REP) - que envolvam uma relação entre o corpo do participante com alguma parte do ambiente físico (inclina/balança o corpo para os lados; balança o corpo com o impulso das pernas; sacode o corpo, balança as pernas; alterna a movimentação dos dedos colocando-os um de cada vez sobre a mesa).

- Locomoção (RL) - deslocamento do participante em relação a pontos fixos do espaço (caminha no vão entre a parede direita e a mesa; volta para a mesa).

- Exame do Kinder ${ }^{\circledR}$ ovo (KO) - contato direto com o Kinder ${ }^{\circledR}$ ovo (olha para o Kinder ${ }^{\circledR}$ ovo; inclina-se na direção do Kinder ${ }^{\circledR}$ ovo; segura o Kinder $®$ ovo; tira o Kinder ${ }^{\circledR}$ ovo da frente).

- Exame da câmera (ECA) - contato com a câmera filmadora (olha para a câmera; vira o rosto em direção à câmera; aponta o dedo indicador para a câmera).

- Exame do sino (ES) - contato direto com o sino (olha para o sino; olha por debaixo do sino; pega o sino).

- Exame do fantoche (FAN) - contato com o fantoche (olha para o fantoche; tira a mão direita/esquerda do fantoche; coloca a mão direita/esquerda dentro do fantoche).

- Expressões faciais (EF) - respostas motoras que envolvam os músculos faciais (aperta os lábios; olhos arregalados e sobrancelhas levantadas; abre a boca).

- Respostas voltadas para o próprio participante (PP) o contato com seu próprio corpo e/ou vestuário (enche a boca de ar; assovia; ri; tosse; faz barulho de ronco).

- Respostas verbais gestuais (VG) - que funcionassem como estímulo evocativo para o ouvinte, sempre direcionada ao outro participante (abre/fecha a mão; dá tchau para a câmera; toca na mão de P; levanta e abaixa os ombros).

- Respostas verbais orais (VO) - que funcionassem como estímulo evocativo para o ouvinte - ele mesmo ou o outro participante (a função evocativa foi identificada a partir das respostas que se seguiram).

Foram estabelecidos dois critérios básicos para a categorização de cada uma das respostas: 1. Uma resposta que tivesse duração superior a dez segundos (intervalo da transcrição) seria tabulada como uma única ocorrência no intervalo que foi iniciada e como outra ocorrência no próximo intervalo; 2. As respostas que ocorressem mais de uma vez durante o intervalo de transcrição e que fosse possível identificar seu início e fim (por exemplo, bater as mãos sobre a mesa) seriam tabuladas conforme o número de ocorrências observadas.

As respostas verbais orais das crianças durante as condições experimentais foram categorizadas. Cada fala foi considerada como uma verbalização até que o outro participante iniciasse outra verbalização e, caso a fala de um participante ultrapassasse o intervalo de 10s, ela seria catalogada como uma nova ocorrência no intervalo seguinte. Com base em Oda (2009), as verbalizações foram classificadas nas seguintes categorias:

- Tatos sobre a condição experimental - descrevem elementos da situação experimental ou relacionados ao próprio comportamento, que pareciam estar sob controle de condições antecedentes (Eu vou tocar o sino!; Ele tá demorando muito! Eu quero tirar um cochilo! Eu vou cochilar!).

- Tatos gerais - descrevem eventos outros na sala experimental (Sabe quando parece que o pé da gente tá formigando? Tem um tanto de formiga; Ai, tá muito frio!).

- Mandos sobre a condição experimental - especificam respostas a serem emitidas pelo outro ou pelo participante, ou ambos e/ou a consequência das mesmas, relacionadas com aspectos das contingências programadas (Isso, faz... fica quietinha sem mexer em nada, nem..;).

- Mandos gerais - especificam respostas a serem emitidas e/ou a consequência das mesmas (Cala a boca! Cala a boca!).

- Tatos + mandos - parecem ter dupla função combinando mandos e tatos (Pex.: Quero fazer xixi! Eu quero ir ao banheiro!).

- Assuntos não relacionados - não atenderam às caracterizações acima tais como, intraverbais, ecoicos e demais operantes verbais não descritos acima (Um, dois, três indiozinhos. Quatro, cinco...).

- Inaudíveis (respostas que não puderam ser transcritas porque os participantes falavam baixo ou por problemas de áudio do equipamento).

Os testes de concordância foram feitos por dois avaliadores analistas do comportamento. Cada avaliador assistia ao vídeo e categorizava a transcrição, de acordo com uma tabela de categorias disponibilizada pelo autor. As categorizações eram então comparadas. Depois foram feitos os cálculos de cada um dos testes de concordância, tanto das categorias não-verbais quanto das verbais. As médias foram: $93 \%$ na condição 'sozinho', 97\% na condição 'fantoche' e 79\% na 
condição 'duplas'. O valor de 79\% de concordância na condição 'duplas' ocorreu devido à discrepância entre os avaliadores nas categorias 'expressão facial', 'próprio participante', 'ambiente' e 'verbais gestuais'.

\section{RESULTADOS}

Todas as crianças declararam preferir dois chocolates ao serem questionadas sobre sua preferência. Das 15 crianças que participaram, 11 esperaram pela volta do experimentador e ganharam dois Kinder ${ }^{\circledR}$ ovos: duas das quatro crianças da condição 'sozinho'(S3 e S4), as três da condição 'fantoche' (F1, F2, e F3) e seis da condição 'duplas' (D1 e D2 ${ }^{1}$; D5 e D6; D7 e D8). Quatro não esperaram $15 \mathrm{~min} e$ ganharam um Kinder® ovo (nenhuma comeu o ovo durante o tempo de espera): duas crianças da condição 'sozinho' (S1 e S2) tiveram um tempo de espera de 9 min e $28 \mathrm{~s}$ e de $3 \mathrm{~min}$ e $50 \mathrm{~s}$, respectivamente, e uma dupla (D3 e D4) esperou por 9 min e 47s e, neste caso, a decisão de tocar o sino foi de apenas um dos participantes da dupla. A condição 'sozinho', na qual não havia controle social planejado, foi a em que menos as crianças esperaram.

1 Por problemas técnicos com a filmagem os dados das categorias de comportamentos da dupla D1 e D2 não serão apresentados na seção de resultados.
Os resultados sugerem que a quantidade de respostas emitidas na sessão afeta a probabilidade de a criança esperar. A Figura 1 mostra a média de respostas por minuto dos participantes que esperaram (barra cinza-claro) e que não esperaram (barra cinza-escuro) em cada uma das condições experimentais e a média de respostas por minuto (marcador) em cada uma das condições. As respostas foram computadas a partir de 14 categorias (baseadas em Kerbauy \& Buzzo, 1991; Danna \& Matos, 1982).

Em cada condição, os participantes que mais esperaram foram os que tiveram o número de respostas por minuto mais alto. Os participantes da condição 'sozinho' foram os que emitiram menor número de respostas por minuto $(\mathrm{R} / \mathrm{min})$ quando comparados com os das outras duas condições experimentais. Os participantes dessa condição apresentaram, em média, 23,8 R/min: os que não esperaram emitiram, em média, $18,9 \mathrm{R} / \mathrm{min}$ e os que esperaram $28,7 \mathrm{R} / \mathrm{min}$. Os participantes da condição 'fantoche' apresentaram, em média, 33,4 R/min. Esse valor é superior ao encontrado na condição 'sozinho', até mesmo para os que esperaram. A condição 'duplas' apresentou a maior média de $\mathrm{R} / \mathrm{min}(42,9 \mathrm{R} / \mathrm{min})$. A média para os que não esperaram foi de $40 \mathrm{R} / \mathrm{min}$ e de $44,4 \mathrm{R} / \mathrm{min}$ para os que esperaram.

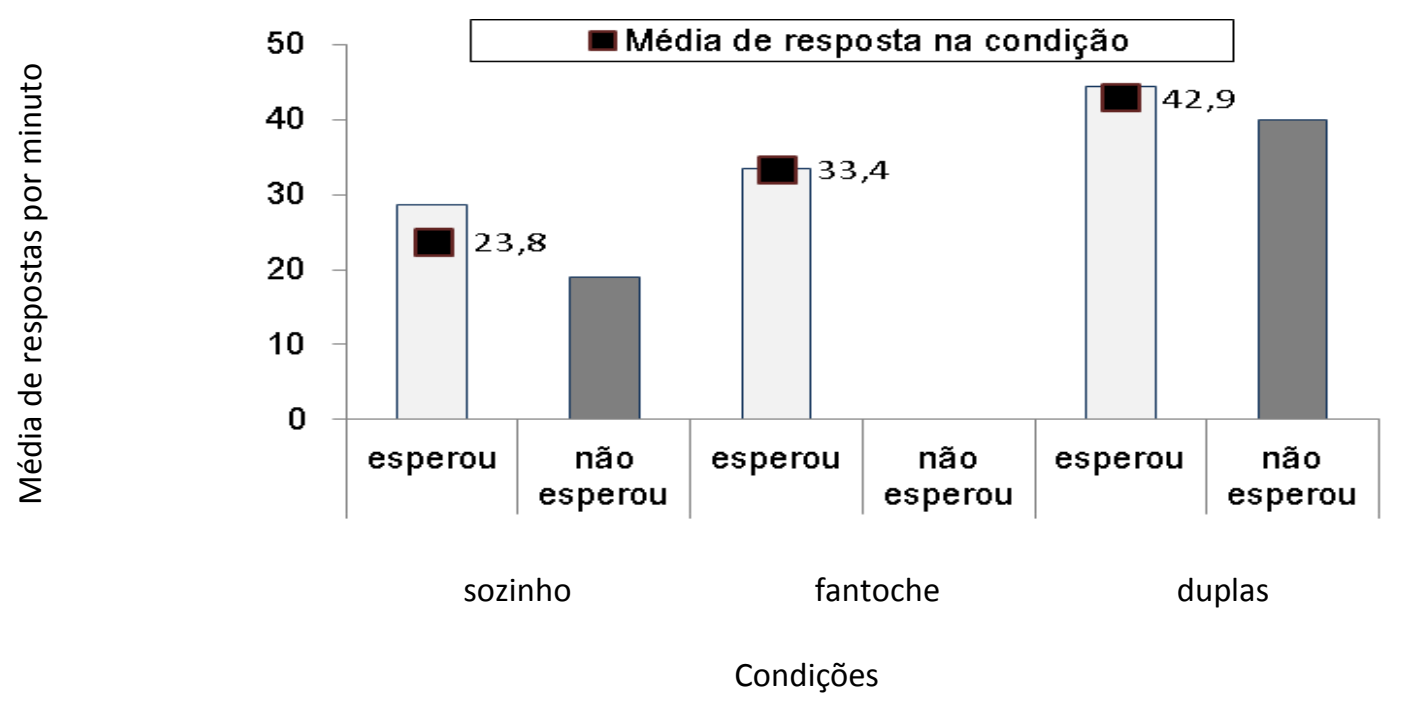

Figura 1. Média de respostas por minuto $(\mathrm{R} / \mathrm{min})$ dos participantes que esperaram (barra cinza- claro) e que não esperaram (barra cinza-escuro) em cada uma das condições experimentais e média de respostas por minuto (marcador) em cada uma das condições experimentais. 
F1
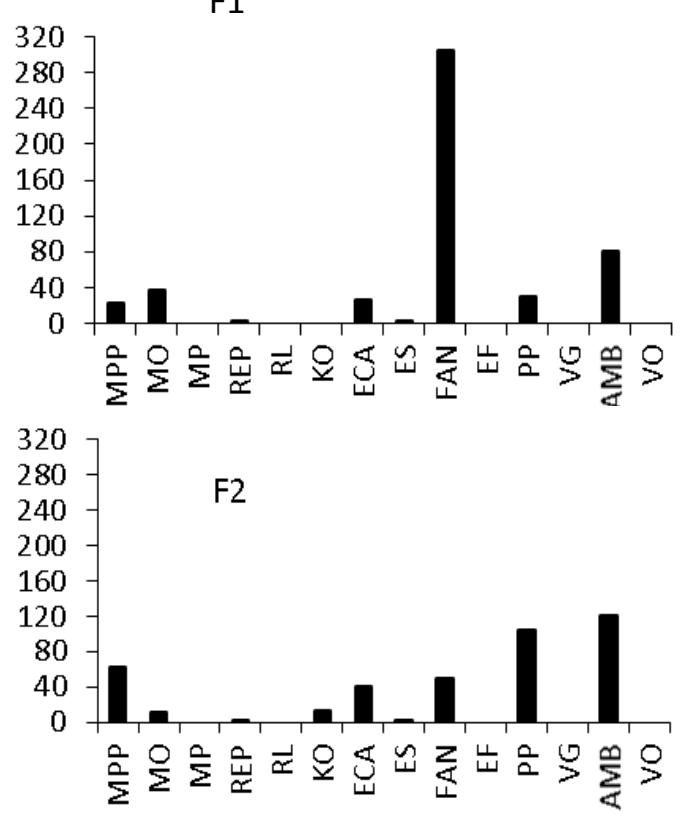

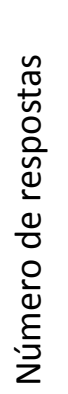
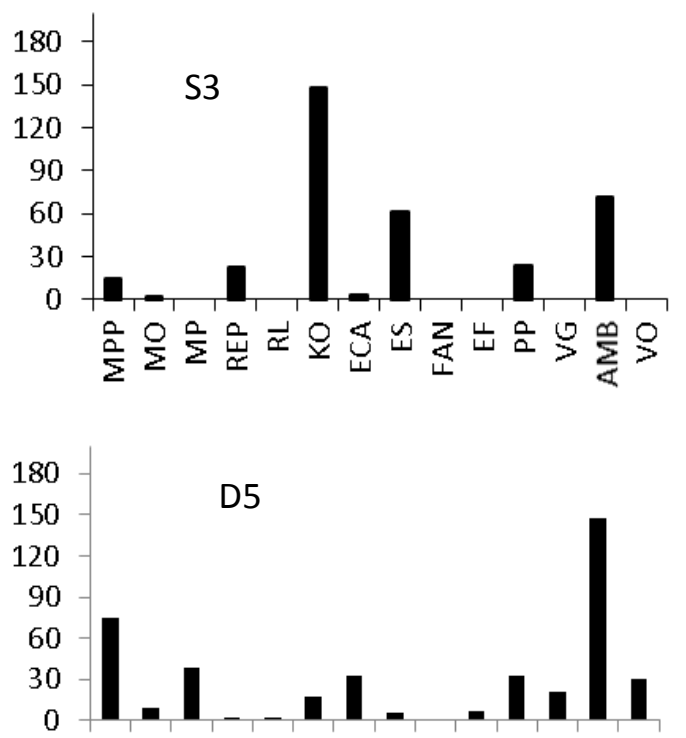

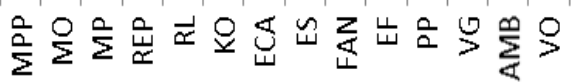

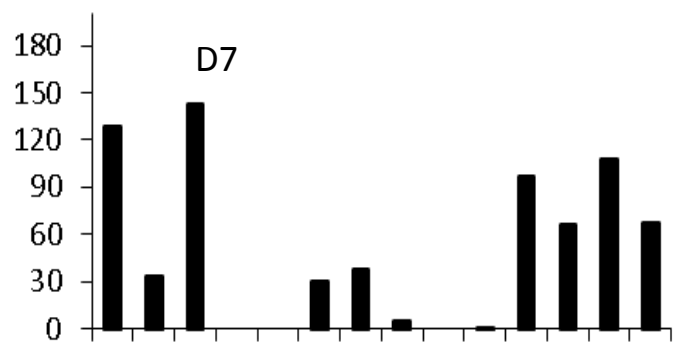

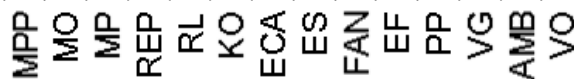

MPP - Mudança de Posição e Postura

MO - Manipulação de Objetos

MP - Manipulação de Pessoas

REP - Respostas Repetitivas

$\mathrm{RL}$ - Respostas de Locomoção

KO - Kinder Ovo

ECA - Exame da Câmera

ES - Exame do Sino

FAN - Fantoche

EF - Expressão Facial

PP - Próprio participante

VG - Verbal Gestual

AMB - Manipulação do Ambiente

VO-Verbal Oral
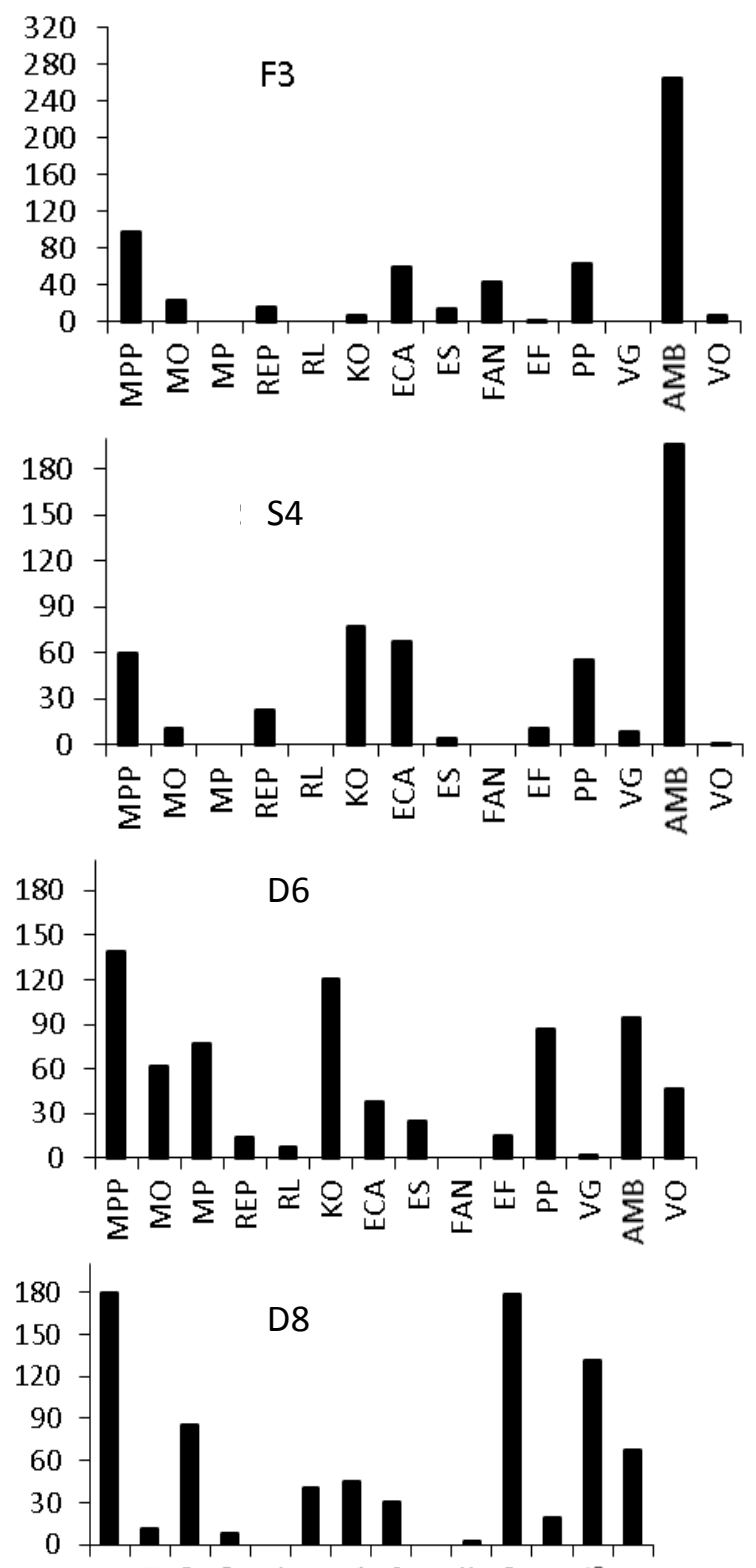

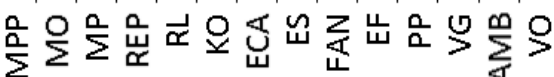

\section{CATEGORIAS}

Figura 2. Número de respostas nas categorias dos participantes que esperaram 15 minutos. 
A Figura 2 apresenta o número de respostas que ocorreram durante o período de espera em cada uma das 14 categorias dos participantes que esperaram nas três condições. Nos painéis superiores estão representadas as respostas de F1, F2 e F3 da condição 'fantoche'; nos painéis intermediários as de S3 e S4 da condição 'sozinho'; nos painéis inferiores as das 'duplas' D5-D6 e D7-D8. O número de respostas nos eixos verticais é igual em cada condição, mas difere entre as condições.

Algumas categorias de respostas foram bastante frequentes para muitos participantes que esperaram: exame ou observação do ambiente (AMB) para as três condições, ações voltadas para o próprio corpo (PP) para duas condições ('sozinho' e 'fantoche') e mudança de postura e posição (MPP) também para duas condições ('fantoche' e 'duplas'). A categoria com maior número de respostas de cada participante não é a mesma para os participantes de uma mesma condição, exceto para a condição 'fantoche' na qual dois dos três participantes apresentaram maior número de respostas de observação do ambiente (AMB) e na condição 'duplas' dois dos quatro participantes analisados apresentaram maior número de respostas de mudança de postura e posição.

Para os dois participantes da condição 'sozinho' que esperaram, as categorias exame e observação do ambiente (AMB) para $\mathrm{S} 4$ e exame do Kinder ${ }^{\circledR}$ ovo $(\mathrm{KO})$ para $\mathrm{S} 3$ foram as mais frequentes. Categorias que envolviam objetos da situação experimental - exame da câmera (ECA) para S2 e exame do sino (ES) para S1 - foram categorias também com grande número de respostas. Apesar de a câmera ter sido colocada em lugar supostamente sem destaque, ela parece ter controlado o comportamento de algumas crianças.

Todos os participantes da condição 'fantoche' esperaram os quinze minutos programados para o término da sessão experimental. 'Fantoche' (FAN) foi a categoria em que F1 concentrou a maioria das respostas.

Apesar da categoria FAN não estar entre as mais frequentes para os outros participantes, a disponibilidade do fantoche afetou o comportamento de F2 e F3 que tiveram entre 43 e 50 respostas, respectivamente. Além de observar o ambiente (AMB) grande número de vezes, duas outras categorias se destacam para estes dois participantes: 'mudança de posição ou postura' (MPP) para F3 e 'respostas voltadas ao próprio participante', para F2. Apenas F3 emitiu algumas respostas verbais orais, que ocorreram no mesmo intervalo em que exibiu respostas direcionadas ao fantoche, o que pode sugerir que ele teve, nesses casos, uma função de audiência.

$\mathrm{Na}$ condição 'duplas', as categorias mais frequentes para as duas duplas que esperaram foram mudança de postura e posição (MPP) para D6 e D8, observação do ambiente (AMB) para D5 e manipulação de pessoas (MP) para D5. Entre as respostas categorizadas como manipulação de pessoas foi identificada, para a dupla que não esperou, a restrição física quando um dos participantes tentava tocar o sino e o outro participante o impedia, abraçando-o.

Algumas características do responder podem ser destacas na condição 'duplas'. Uma delas é o grande número de respostas dos participantes, já identificado na média de respostas por minuto (Figura 1) e que também pode ser identificado no alto número de respostas nas categorias (Figura 2).

Outra característica, na condição 'duplas', é que as respostas foram, em geral, mais igualmente distribuídas (Figura 2) nas várias categorias do que na condição 'fantoche' e para um participante da condição 'sozinho'. A Figura 3 mostra o número de respostas por participantes que esperaram os 15 minutos e a porcentagem de categorias em que as respostas se distribuíram, calculada a partir das categorias possíveis em cada condição (nas condições 'sozinho' e 'fantoche', não poderiam ocorrer respostas manipulação de pessoas e fantoche só estava presente em uma condição). Na condição 'duplas', observa-se maior número de respostas que se dispersam entre maior número de categorias (em $100 \%$ das categorias possíveis, para D5 e D6; 92\% para D8) e várias delas com números altos de respostas (Figura 2). Na condição 'fantoche', as respostas em menor número, se dispersam em um número menor de categorias (entre $53,8 \%$ e $76,9 \%$ ), assim como para um participante da condição 'sozinho' (72,7\% para S3). Para a maioria dos participantes da condição 'fantoche' (F1 e F3), a categoria mais frequente concentrou alto número de respostas $(42,2 \%$ e $60,7 \%$ das respostas, respectivamente). Na condição 'duplas', para três dos participantes esta concentração ocorreu em torno de 20 e $22 \%$. Isto indica que na condição 'duplas', em geral, ocorreu maior variabilidade de respostas. 


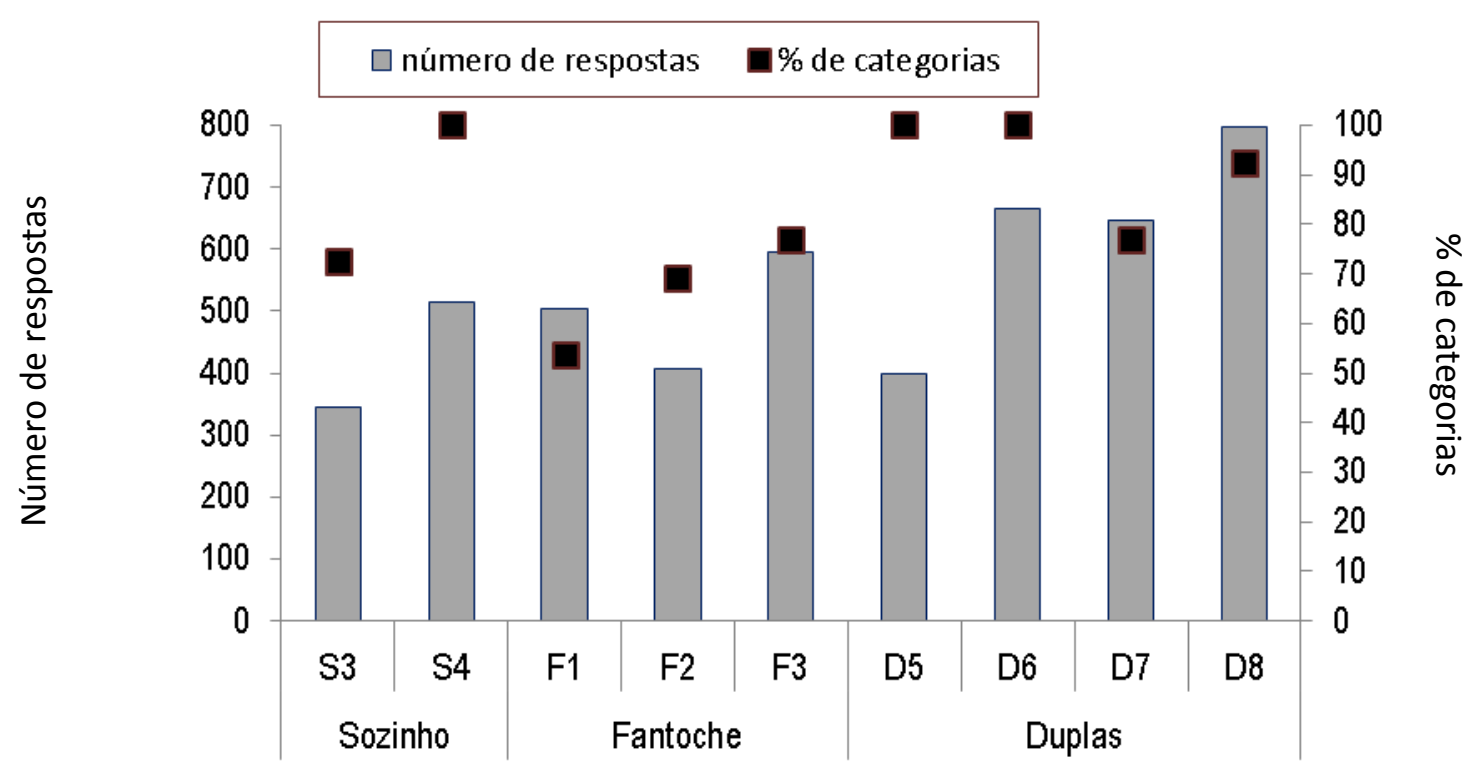

Figura 3. Número de respostas nos 15 minutos de espera (barra) e porcentagem de categorias nas quais as respostas se distribuíram (marcador) por participante.

A partir da análise das respostas em diferentes categorias, pode-se identificar a presença de possíveis controles sociais sobre o responder. $\mathrm{Na}$ condição 'duplas', parte importante do ambiente foi o outro participante e isso se refletiu na alta ocorrência de respostas da categoria 'manipulação de pessoas' (MP) e 'respostas verbais orais' (VO), como se observa na Figura 2.

Na Tabela 1 são destacados o número de respostas em algumas categorias relacionadas a esse controle pelo outro e a porcentagem dessas respostas em relação ao total de respostas na sessão, na condição 'duplas'. A análise da porcentagem de respostas direcionadas para o outro participante (soma das respostas da categoria 'manipulação de pessoas', 'verbal gestual' e 'verbal oral') indica que os participantes emitiram entre 17,3 e $38,5 \%$ do total de suas respostas direcionadas ao colega e que, em todas as duplas, um dos participantes sempre respondeu com maior frequência do que o outro.

Tabela 1

Número de Respostas nas Categorias que Envolveram o Outro Participante na Condição 'Duplas' e Porcentagem de Respostas nessas Categorias em Relação ao Total de Respostas ao Longo dos 15 min de Espera.

\begin{tabular}{|c|c|c|c|c|c|c|}
\hline \multirow{3}{*}{ Participantes } & \multirow{3}{*}{$\begin{array}{l}\text { Manipulação de } \\
\text { pessoas } \\
\text { (MP) }\end{array}$} & \multirow{3}{*}{$\begin{array}{l}\text { Verbal } \\
\text { gestual } \\
\text { (VG) }\end{array}$} & \multirow{3}{*}{$\begin{array}{l}\text { Verbal } \\
\text { oral } \\
\text { (VO) }\end{array}$} & \multicolumn{3}{|c|}{ Total de respostas } \\
\hline & & & & \multicolumn{2}{|c|}{$\begin{array}{c}\text { Direcionadas para o } \\
\text { outro }\end{array}$} & \multirow{2}{*}{$\begin{array}{c}\text { Na sessão } \\
\text { N }\end{array}$} \\
\hline & & & & $\mathrm{n}$ & $\%$ & \\
\hline D3 & 61 & 30 & 55 & 106 & 26,3 & 403 \\
\hline D4 & 47 & 19 & 50 & 116 & 29,2 & 397 \\
\hline D5 & 38 & 21 & 30 & 89 & 21,1 & 421 \\
\hline D6 & 77 & 02 & 47 & 126 & 17,3 & 728 \\
\hline D7 & 143 & 66 & 67 & 276 & 38,5 & 717 \\
\hline D8 & 85 & 19 & 67 & 171 & 21,4 & 798 \\
\hline
\end{tabular}


Outras categorias, não destacadas na Tabela 1 , poderiam ainda indicar controle social. Na condição 'duplas', muitas respostas categorizadas como AMB consistiram em observar o outro participante. Todos os participantes de todas as condições examinaram a câmera, o que sugere que poderiam estar respondendo sob controle de um observador. Na condição 'duplas', as respostas 'verbais orais' e/ou 'verbais gestuais' indicaram que alguns participantes descobriram a existência da câmera filmadora, enquanto que nas demais condições, em alguns casos, a criança olhava para a câmera ou fazia algum tipo de gesto em direção a ela. Nesses exemplos, pode-se supor algum controle social, mesmo sem o experimentador estar presente na situação.

$\mathrm{Na}$ condição 'duplas' foi possível identificar vários controles sociais, entre eles os que ocorreram por meio do comportamento verbal oral. As respostas 'verbais orais' foram classificadas em subcategorias e ocorreram quase que exclusivamente na condição 'duplas'. A Tabela 2 apresenta o número de respostas 'verbais orais' de acordo com as subcategorias para os participantes que as emitiram e a porcentagem de tais respostas na sessão. Os participantes D3 a D8 fizeram parte da condição 'duplas'; S4 participou na condição 'sozinho'; e F3 da condição 'fantoche'. Para estes dois últimos participantes, estas respostas estiveram abaixo de $1 \%$ das respostas da sessão. Apenas uma resposta verbal oral ANR foi emitida pelo participante da condição 'sozinho' e sete respostas, pelo participante da condição 'fantoche'. As subcategorias 'tatos' e 'mandos sobre a condição experimental' foram as respostas 'verbais orais' mais frequentes, respectivamente 73 e 52 respostas. Exceto para D7 e D3, ocorreram mais 'tatos da situação experimental' que 'mandos'. Os participantes que tiveram mais respostas orais em relação ao número total de respostas na sessão foram D3 e D4, que não esperaram.

$\mathrm{Na}$ condição fantoche, não é possível identificar se este teve a função de ouvinte.

Tabela 2

Número de Respostas Verbais Orais de Cada Participante nas Subcategorias e Porcentagem de Respostas Verbais Orais na Sessão (S4 - Condição 'Sozinho'; F3 - condição 'Fantoche'; D3 a D8 - Condição 'Duplas”').

\begin{tabular}{|c|c|c|c|c|c|c|c|c|c|}
\hline \multirow{2}{*}{ Subcategorias } & \multicolumn{9}{|c|}{ Número de respostas verbais orais } \\
\hline & D3 & D4 & D5 & D6 & D7 & D8 & $\mathrm{S} 4$ & F3 & Total \\
\hline Tato sobre a Condição Experimental (TCE) & 14 & 15 & 06 & 12 & 08 & 15 & 00 & 03 & 73 \\
\hline Tatos Gerais (TC) & 07 & 04 & 09 & 05 & 01 & 11 & 00 & 00 & 37 \\
\hline Mando sobre a Condição Experimental (MCE) & 16 & 06 & 03 & 06 & 13 & 08 & 00 & 00 & 52 \\
\hline Mandos Gerais (MG) & 06 & 05 & 00 & 07 & 02 & 03 & 00 & 01 & 24 \\
\hline Mando + Tato $(\mathrm{M}+\mathrm{T})$ & 01 & 03 & 06 & 07 & 04 & 09 & 00 & 00 & 30 \\
\hline Assuntos não relacionados (ANR) & 19 & 16 & 01 & 02 & 02 & 07 & 01 & 00 & 48 \\
\hline Respostas inaudíveis & 04 & 04 & 06 & 11 & 45 & 23 & 00 & 03 & 96 \\
\hline TOTAL & 67 & 53 & 31 & 50 & 75 & 76 & 01 & 07 & 360 \\
\hline$\%$ de respostas verbais & 19,0 & 15,3 & 7,8 & 7,5 & 11,6 & 9,3 & 0,0 & 0,1 & \\
\hline
\end{tabular}

$\mathrm{Na}$ análise das 'respostas verbais orais', foi possível identificar que a condição de esperar pode ter se constituído em condição com certa aversividade. Por exemplo, nas verbalizações: "Ele tá demorando muito! Eu quero tirar um cochilo! Eu vou cochilar!" e "Tá me deixando maluca de vontade de comer o ovo".
Várias formas de controle social puderam ser observadas por meio das verbalizações. Em uma verbalização pôde-se identificar o uso de ameaça por um dos participantes para que o outro participante não tocasse o sino - "Vou contar pra tia". Em outra, identifica-se uma 
solicitação: “Ah, não! Não toca não, por favor! Não! Eu tenho medo! Eu quero ganhar outro ovo!".

Uma peculiaridade observada nessa condição foi que os mandos de um participante eram geralmente reforçados pelo desempenho do outro participante, visto que nas transcrições das respostas verbais, em alguns casos um dos participantes de uma dupla obedecia aos mandos dados pelo outro participante: quando um dos participantes disse "Eu estou com sono.", o outro respondeu "Então vamos tirar uma soneca." e ambos se deitaram sobre a mesa.

Em outras verbalizações foi observada uma possível manipulação do ambiente quando um dos participantes mudava de assunto no momento em que um dos participantes indicava que iria tocar o sino. Observouse ainda que os participantes se engajavam em atividades que envolviam comportamento verbal oral que podem ter facilitado o esperar, como quando cantavam juntos ou contavam histórias. Ou ainda algumas descrições do próprio comportamento, que podem ter tido a função tanto de tato como de mando, que produziu um comportamento de imitação do outro participante, como por exemplo, quando um dos participantes diz "vou dormir" ou "vou ficar quietinha" e o outro faz o mesmo.

\section{DISCUSSÃO}

O objetivo deste estudo foi verificar os efeitos do controle social no comportamento de esperar por reforçadores de maior magnitude atrasados (autocontrole), em crianças. Para isto foram manipuladas três condições. Em uma delas a criança esperava sozinha, supostamente sem controle social presente, como tem sido investigado em estudos anteriores (Mischel \& Ebbesen, 1970; Mischel et al. 1972; Kerbauy, 1981; Kerbauy \& Buzzo, 1991). Duas novas condições, em que se pode supor um controle social, foram planejadas: uma em que um fantoche poderia assumir função de ouvinte estava disponível, e outra em que uma criança esperava com outra criança.

Estudos realizados tinham identificado resultados distintos sobre efeitos da presença do estímulo: em alguns estudos esperar na presença do estímulo diminuía a probabilidade de esperar (Mischel \& Ebbesen, 1970, Mischel et al. 1972), em outro a probabilidade era indiferente (Kerbauy \& Buzzo, 1991). No presente estudo, nas três condições investigadas os estímulos estiveram à vista. A comparação do tempo de espera e dos comportamentos em condições em que a criança esperava 'sozinha' com as condições 'fantoche' e 'dupla' poderia evidenciar os efeitos de controles sociais presentes ou não nestas condições. Variáveis relacionadas à complexidade do ambiente, especialmente aquelas relacionadas ao ambiente social, poderiam favorecer respostas de autocontrole?

Houve diferenças entre os participantes das várias condições em relação ao tempo de espera. A maioria das crianças esperou tendo o chocolate à sua frente (11 dos 15 participantes). Entretanto, quando se analisam os tempos de espera em relação às condições, identifica-se que na condição 'sozinho', em que controles sociais planejados não estiveram presentes, houve, proporcionalmente, menor número de participantes $(50 \%)$ que permaneceram esperando os 15 minutos necessários para obter dois ovos. Nas duas condições em que foram planejados possíveis controles sociais, a maioria dos participantes esperou: todos $(100 \%)$ na qual o fantoche poderia ser manipulado e seis dos oito participantes das duplas (67\%). Estas alterações no ambiente produziram algumas diferenças no comportamento dos participantes, que devem ser consideradas.

O número de respostas por minuto esteve relacionada à espera, visto que os participantes que esperaram foram os que emitiram maior número de respostas, visto pelas médias de $\mathrm{R} / \mathrm{min}$ emitidas apresentadas na Figura 1. Os participantes da condição 'sozinho' tiveram menores médias de respostas por minuto e os da condição 'duplas', maiores. As médias dos participantes que esperaram foram, em cada condição, maiores do que as dos participantes que não esperaram.

A diversidade de respostas emitidas pelos participantes permitiu a classificação em 14 diferentes categorias. Além de maior quantidade de respostas nas diferentes categorias, houve maior variabilidade na condição em que crianças esperavam em duplas. As respostas se distribuíram mais entre mais categorias nesta condição do que nas outras e em maior porcentagem de categorias diferentes. Identifica-se, nas outras condições, mais participantes que concentram suas respostas em poucas categorias. Este pode ser um indicativo de que a maior variabilidade, aqui avaliada pela semelhança na distribuição de respostas entre as várias possibilidades, aumenta as chances de que o indivíduo espere por estímulos reforçadores maiores e atrasados.

Estudos como os de Mischel e Ebbesen (1970),

Kerbauy (1981), Fernandes (2005), Menezes (2007), Correia e Micheletto (2009) e Canavarros (2009) identificaram as respostas emitidas por participantes durante o período de espera. Muitas das respostas citadas por esses autores foram observadas neste trabalho dentro das categorias 'próprio participante', 'mudanças de posição e postura', 'verbais orais' entre outras, como por exemplo, apoiar a cabeça sobre os braços, falar consigo mesmo, cantar, brincar com as mãos ou tentar dormir.

Kerbauy (1981), Kerbauy e Buzzo (1991) e Mischel et al. (1972) apresentaram como resultados importantes o fato de que o que se faz enquanto se espera tem influência no tempo esperado. Pelos resultados do presente estudo, não se identificou para todos os participantes uma categoria específica de maior ocorrência, apesar de algumas categorias terem sido bastante frequentes para vários participantes. Mischel et al. (1972) concluíram que o tempo de espera é reduzido quando não se disponibiliza algum tipo de atividade para a criança. No presente estudo, os participantes que esperaram foram os mais ativos; os participantes das condições 'fantoche' e 'duplas', que em geral esperaram, tiveram mais elementos disponibilizados no ambiente (um fantoche ou outra pessoa) do que aqueles da condição 'sozinho'.

Nos estudos de Grosh e Neuringer (1981), Sales (2006) e Moreira e Abreu-Rodrigues (2008), os autores afirmaram que, se um organismo tiver a oportunidade de emitir uma resposta alternativa durante o tempo de espera, 
aumenta-se a probabilidade da obtenção do reforçador de maior magnitude, porém atrasado, devido ao fato de que essas respostas produzem seus próprios reforçadores. $\mathrm{Na}$ condição 'sozinho', identifica-se para os que esperaram respostas mais frequentes de 'exame do Kinder @ ovo' e 'observação do ambiente'.

$\mathrm{Na}$ condição 'fantoche', outras respostas foram possíveis. Todas as crianças tiveram muitas respostas classificadas como 'fantoche', especialmente no desempenho do participante F1 que passou os $15 \mathrm{~min}$ de espera movimentando o fantoche nas mãos. Apenas um participante emitiu poucas (sete) respostas 'verbais orais' (de sete respostas, três classificadas como 'tatos sobre a condição experimental'). Como ocorreram enquanto manipulava o fantoche, pode-se supor que este estivesse tendo a função de audiência. Para os outros participantes não foi possível concluir se o fantoche exerceu tal função. As crianças não foram expostas a uma história de reforçamento diferencial que permitisse estabelecer ao fantoche função de audiência, como ocorreu no estudo de Pasquinelli (2007); isto pode ter dificultado que o fantoche assumisse esta função. $\mathrm{O}$ fantoche pode ter favorecido a criança esperar, dado que ele pode ter permitido que as crianças realizassem outras respostas que produziam consequências reforçadoras durante a espera. Seria importante em próximos estudos delinear procedimentos em que se crie uma história experimental entre o fantoche e a criança, para que se possa verificar se ele adquire diferentes funções de audiência - como funções evocativas do comportamento do falante, como no estudo de Pasquinelli (2007), e a seguir, avaliar seus efeitos sobre o tempo de espera e sobre os comportamentos, especialmente o verbal oral.

Os dados referentes à média de $\mathrm{R} / \mathrm{min}$ e das porcentagens de respostas direcionadas para o outro participante na condição ‘duplas' fortalece a hipótese de que um ambiente social mais complexo possibilitou mais oportunidades para responder. Estas oportunidades podem ser observadas nas várias categorias relacionadas ao outro (Tabela 1). A análise do comportamento verbal oral revela que, por meio de respostas que possivelmente tinham a função de mandos e tatos relacionados à condição experimental, os participantes geralmente buscavam controlar o comportamento do outro, por exemplo, de maneira a evitar que ele tocasse o sino, ou levá-lo a atentar para estímulos diferentes do sino. Isto ocorreu por meio de ameaça, como quando uma criança diz que vai contar para a professora, ou que o experimentador as está observando pela câmera; ou quando parece criar condições concorrentes à resposta de tocar o sino, levando o outro a se engajar em uma brincadeira de contar história por um período prolongado; cantar; ou convidar a outra participante para dormir, o que pode ter transformado a condição de espera em uma situação menos aversiva.

Neste trabalho, o comportamento de cada membro da dupla determinava em parte o resultado da sessão. $\mathrm{Na}$ dupla que não esperou, um dos membros procurou de diversas maneiras impedir física e verbalmente (estes foram os dois participantes que emitiram maior porcentagem de comportamento verbal na sessão) que o outro membro tocasse o sino. Nesta dupla pode-se identificar que o ambiente social dispôs consequências adicionais às condições manipuladas pelo próprio indivíduo. Skinner (1953/1965) aponta que a comunidade pode tornar o autocontrole "ligeiramente mais provável pelo estabelecimento de consequências aversivas contingentes a uma falha de controle". Tais consequências aversivas puderam ser identificadas na dupla que não esperou quando um dos membros verbalizou: "Cala a boca! Eu vou contar pra tia isso!" e "Eu vou contar pra tia que a gente não ganhou porque você tocou!".

As respostas 'verbais orais' (VO) e 'gestuais' (VG) parecem confirmar que, em condições sociais, o controle verbal entre os membros seja uma variável importante no entendimento do comportamento dos pares.

Concluindo, é importante perceber que parte do comportamento de esperar por reforçadores de maior magnitude é aprendida pelas condições geradas pelo ambiente social. $\mathrm{O}$ indivíduo, ao se comportar de maneira a esperar por reforçadores maiores e atrasados, garante, em parte, uma condição menos aversiva e mais reforçadora para si e para seu grupo.

Neste processo, muitos comportamentos emitidos pelos participantes durante o período de espera podem ser considerados como respostas que momentaneamente produzem reforçadores e diminuem a aversividade do atraso das consequências.

Em suma, os resultados mostraram que ambientes mais complexos permitem que indivíduos respondam com maior frequência e de maneira mais variada enquanto esperam por reforçadores maiores e atrasados. Também mostraram que os estímulos experimentais exerceram controle no responder dos participantes por terem se tornado possíveis brinquedos ou por criarem ambiente social durante a espera. Os resultados mostraram ainda, que o ambiente social tem um controle considerável sobre o comportamento de crianças e é condição que favorece a explicitação de alguns controles.

Uma das limitações do estudo, no entanto, é seu caráter ainda exploratório. Seria importante que em estudos futuros fossem realizados novos delineamentos experimentais em que o controle social fosse o foco principal, complementando a compreensão dos controles sociais que operam nas condições propostas para investigar autocontrole. Uma das possibilidades seria delineando experimentos em condição de duplas em que a consequência reforçadora pudesse ser individualizada. Outra sugestão refere-se aos delineamentos de controle. Este estudo utilizou um delineamento de grupos, entretanto cada condição teve poucos participantes. Seria importante a replicação com maior número de crianças em cada grupo. Dado que o estudo de Kerbauy e Buzzo (1991) já identificou que a reexposição ao procedimento leva ao estabelecimento de autocontrole, um delineamento em que o sujeito seria seu próprio controle poderia ser inadequado.

\section{REFERÊNCIAS}

Canavarros, D. A. P. (2009). Autocontrole: Um estudo sobre o efeito da manipulação do atraso do reforço a partir de um procedimento de fading. Dissertação de 
Mestrado. São Paulo: Pontifícia Universidade Católica de São Paulo. Retirado de http://www.sapientia.pucsp.br/tde_busca/arquivo.php?c odArquivo $=9054$

Correia, T. C., \& Micheletto, N. (2015). Efeitos de um marcador temporal sobre respostas de escolha por maior atraso e magnitude do reforço em crianças. Estudos de Psicologia (Natal), 20(2), 102-113.

Danna, M. F., \& Matos, M. A. (1982). Ensinando observação: Uma introdução. São Paulo: Edicon.

Fernandes, G. L. (2005). Comportamento de escolha: Um estudo sobre o efeito da variação simultânea da magnitude e do atraso do reforço a partir da replicação sistemática de Ferreira (2002). Dissertação de Mestrado. São Paulo: Pontifícia Universidade Católica de São Paulo. Retirado de http://www.sapientia.pucsp.br/tde_busca/arquivo.php?c odArquivo $=14070$

Ferster, C. B., Numberger, J. I., \& Levitt. E. E. (1973). The control of eating. Em M. R. Goldfried, \& M. Merbaum. Behavior change through sefl-control (pp. 195-212). New York: Holt, Rinehart and Winston.

Fonai, A. C. V., \& Sério, T. M. A. P. (2007). O conceito de audiência e os múltiplos controles do comportamento verbal. Revista Brasileira de Terapia Comportamental e Cognitiva, 9, 349-360.

Grosh, J., \& Neuringer, A. (1981). Self-control in pigeons under the Mischel paradigm. Journal of the Experimental Analysis of Behavior, 35, 3-21.

Hanna, E. S., \& Todorov, J. C. (2002). Modelos de autocontrole na análise experimental do comportamento: Utilidade e crítica. Psicologia: Teoria e Pesquisa, 18, 337-343.

Kerbauy, R. R. (1981). Um estudo sobre espera de recompensa: Possibilidades que essa situação apresenta. Boletim de Psicologia, 33, 52-57.

Kerbauy, R. R., \& Buzzo, M. P. (1991). Descrição de algumas variáveis no comportamento de esperar por recompensas previamente escolhidas. Psicologia - USP, 2, 77-84.

Logue, A. W., \& Peña-Correal, T. E. (1984). Responding during reinforcement delay in a self-control paradigm. Journal of the Experimental Analysis of Behavior, 41, 267-277.

Lougue, A. W., \& Chavarro, A. (1992). Self-control and impulsiveness in preschool children. The Psychological Record, 42, 189-204.

Menezes, M. S. T. B. (2007). Autocontrole: Um estudo sobre o efeito da variação simultânea da magnitude $e$ do atraso do reforço e da possibilidade de realização de atividades distrativas. Dissertação de Mestrado. São Paulo: Pontifícia Universidade Católica de São Paulo. Retirado de

http://www.sapientia.pucsp.br/tde_busca/arquivo.php?codA rquivo $=4809$
Mischel, W., \& Ebbesen, E. (1970). Attention in delay of gratification. Journal of Personality and Social Psychology, 16, 329-337.

Mischel, W., Ebbesen, E., \& Zeiss, A. R. (1972). Cognitive and intentional mechanisms in delay of gratification. Journal of Personality and Social Psychology, 21, 204218.

Moreira, J. M., \& Abreu-Rodrigues, J. (2008). Atividade durante $\mathrm{o}$ atraso: Efeitos sobre a escolha entre autocontrole e impulsividade. Revista Brasileira de Análise do Comportamento, 4, 53-70.

Moroz, M. (1991). Resolução de problemas: Problema a ser solucionado conceitual e empiricamente. Uma análise da interpretação de B. F. Skinner. Tese de doutorado. São Paulo: Pontifícia Universidade Católica de São Paulo.

Neef, A. A., Bicard, D. F., \& Endo, S. (2001). Assessment of impulsivity and the development of self-control in student with deficit hyperactivity disorder. Journal of Applied Behavior Analysis, 34, 397-408.

Oda, L. (2009). Investigação das interações verbais em um análogo experimental de metacontingência. Dissertação de Mestrado. São Paulo: Pontifícia Universidade Católica de São Paulo. Retirado de http://www.sapientia.pucsp.br/tde_busca/arquivo.php?c odArquivo=9404

Pasquinelli, R. S. H. (2007). Um estudo sobre o estabelecimento do controle e da generalização da audiência sobre o comportamento. Dissertação de Mestrado. São Paulo: Pontifícia Universidade Católica de São Paulo. Retirado de http://www.sapientia.pucsp.br/tde_busca/arquivo.php?c odArquivo=4295

Rachlin, H. (2000). The science of self-control. Cambridge: Harvard, University Press.

Rachlin, H., \& Green, L. (1972). Commitment, choice and self-control. Journal of the Experimental Analysis of Behavior, 1, 15-22.

Sales, T. M. (2006). Um estudo sobre as atividades nas quais os sujeitos se engajam durante o intervalo entre respostas que produzem reforço. Dissertação de Mestrado. São Paulo: Pontifícia Universidade Católica de São Paulo. Retirado de http://www.sapientia.pucsp.br/tde_busca/arquivo.php?c odArquivo=2743

Siegel, E., \& Rachlin, H. (1995). Soft commitment: Selfcontrol achieved by response persistence. Journal of the Experimental Analysis of Behavior, 64, 117-128.

Skinner, B. F. (1965). Science and human behavior. New York: The Free Press. (Trabalho originalmente publicado em língua inglesa em 1953).

Skinner, B. F. (1992). Verbal behavior. Acton: Copley Publishing. (Trabalho originalmente publicado em língua inglesa em 1957). 